\title{
CONSTRUCTION INDUSTRY BUSINESS PROCESSES MODELED WITH OBJECT-ORIENTED APPROACH
}

\author{
Chian-Hsueng Chao ${ }^{\dagger}$, Ahmad Hadavi ${ }^{\dagger *}$, Wei Lo ${ }^{\ddagger}$, and Raymond J. Krizek ${ }^{\dagger}$ \\ ${ }^{\dagger}$ Department of Civil Engineering, Northwestern University, Evanston, Illinois, USA \\ ${ }^{\ddagger}$ Department of Construction Engineering, National Kaohsiung First University of Science \\ and Technology, Taiwan, ROC \\ *a-hadavi@northwestern.edu
}

\begin{abstract}
For the construction industry, the demands for optimization and greater efficiency become particularly urgent when the flow of project information extends beyond the borders of organizations. Driven by the need to attain even greater corporate competitive advantages, many business philosophies advocate the use of "the power of information technology to radically redesign business processes." However, the adoption of IT in organizations and the configuration of IT in direct support of their business is a very complex process. As one step toward a solution, this paper focuses on the development of an Object-Oriented model for construction practices. An Object-Oriented approach is used to map the corporate business process with IT in terms of a series of reusable business objects, which encapsulate complex business rules. The major advantages of this approach are (a) the tedious redesign efforts of information systems can be waived and (b) applications can run on different platforms through Internet/Intranet connectivity. In contrast to an isolated IT system, this approach allows the construction business process to permeate different organizations, and communication in this system becomes process-to-process oriented.
\end{abstract}

Keywords: IT (Information Technology), BPR (Business Process Reengineering), OMT (Object Modeling Technique), UML (Unified Modeling Language), CORBA (Common Object Request Broker Architecture)

\section{INFORMATION TECHNOLOGY IN THE CONSTRUCTION INDUSTRY}

Due to its fast pace and tight schedule, the construction industry is always very competitive, and this is especially true in a volatile economic environment. Construction projects are characterized by their inherent complexities and diversities and by the non-standardized nature of their production process. Thus, when introducing modern computer technology into this industry, the focus must be on the integration of cost and scheduling systems, because there are the key to improving the quality and efficiency of a project and shortening its duration $[1,2]$. Although some studies have been directed toward the integration of diverse managerial functions (engineering, contract administration, quality control, accounting, commercial transactions, and reporting) on major projects, no satisfactory general solution has emerged due to the complexity of the interactions and the inflexibility of the methods used by diverse groups on different projects. Accordingly, information technology (IT) has, in effect, tended to fragment in the construction industry, because different organizations are at the different stages of IT implementation and simply cannot "talk" to each other. The reason is that the software architecture has thus far been designed in an ad hoc fashion primarily to perform individual business functions, such as scheduling, cost estimation, purchasing, inventory management, or financial accounting. In many construction companies, such function-oriented applications gave rise to an unmanageable maze of system components, and data could not be easily transmitted to other partners. This required that interfaces be developed to link the various applications. This problem was compounded by the fact that, once instituted, function-oriented structures could not be transformed into process-oriented structures; as a result, companies sacrificed flexibility and the ability to introduce change. This phenomenon, which is characterized by a high degree of internal integration with very loose or non-existent external connections, is called "Islands of Automation." [3]

Current economic forces and heightened competitive pressures are steadily driving companies to adopt a new type of agile, responsive, and 
organizational structure to fit into the global spectrum of business. New forms of organization, design automation, and numerous other technological advances have now made it possible for an organization to be more process-aware and costeffective at the same time. With the introduction of Business Process Reengineering (BPR) in the 1990s, many companies reevaluated their organizational structure and core business processes and they developed radical redesigns to achieve dramatic improvement in critical contemporary measures of performance, such as cost, quality, service, and speed. Most BPR issues accorded information technology (IT) a central role in these redesigns. The most important aspect of BPR is the way in which business practices are captured in the models that are used to guide the IT system development and implementation. The results of this merger of ideas are process-oriented business solutions, intertwined with the IT of client/server computing.

In the 1990s, two technological trends emerged to enable the more complete integration of critical business processes; these are (a) new, more productive, and cost-effective platforms for client/server computing and (b) innovative processintegrated business solutions. These trends have increased the ability of companies to be more responsive to customers, market changes, and global competitions, and they have eliminated wasteful and unnecessary layers of decision-making by giving more power and responsibility to individuals. As a consequence, companies can take better advantage of globalized business practices.

So far, the construction industry has done little about the alignment of IT and BPR efforts, because construction activities involve a variety of professionals, whose information systems are attuned primarily to their own areas of interests. It is difficult to maintain broad view of information systems that cover all phases of a project life cycle and run business processes throughout different organizations; the latter is called "inter-enterprise process." This paper will illustrate how the latest Object-Oriented modeling technique, client/server web technology, and enterprise supply chain management concepts can be used to build an Adaptive Business Information System (ABIS) with inter-enterprise process capability for construction practices. The goal is to increase the ability of construction companies to enhance communication among members and align their actions toward a common goal. This architecture will enable the construction team to retain dynamic equilibrium while moving forward at an ever-increasing speed.

\section{OBJECT-ORIENTED MODELING OF CONSTRUCTION PRACTICES}

Modeling construction business processes with an organizational structure is very complicated, not to mention mapping hundreds of business processes in the detail of the enterprise information system; however, the Object-Oriented approach simplifies the problem. Following are two important paradigms to guide the modeling efforts: the General Systems Theory (GST) and Object Orientation. One provides a way of defining the general characteristics and properties of all systems (viewing an organization as a system) and the other provides a way to organize and present an understanding of these systems. Together they provide a powerful means of modeling enterprise systems.

\subsection{The General Systems Theory}

The basic concept of the General Systems Theory is that systems have objectives. A system exists in an environment and thus interacts and conducts exchanges with that environment [4]. The elements of a system are interrelated entities (which have objective or physical reality) which can perform certain functions that produce the output. The relations between these entities enable the system to act as a whole with its special system capabilities. In modern terminology, the term "entity" has given way to the term "object" or "component" in an ObjectOriented Analysis. Hence, an organization can be modeled as a "system" of inter-related components that work together to achieve the overall objective of the whole. The business components of an organization include people, processes, events, machines, and information, and these combine to produce the products or output of the organization. Accordingly, a General System Theory provides an "object" view of the organization in object modeling efforts.

\subsection{Porter's Value Chain}

As mentioned earlier, BPR uses IT to radically redesign core business processes in response to key competitive factors. These competitive factors can be derived from the Porter's value chain [5] concept that divides the organization into a set of generic functional areas, which can be further divided into a series of value activities. There are two distinct types of functional area in the value chain: primary and support; primary activities are concerned with the direct flow of production (such as inbound logistics, operations, outbound logistics, marketing, sales, and service), whereas support activities (firm infrastructure, human resource management, technology, and procurement) support the primary 
activities and each other. Starting with its generic value chain categories, a firm can subdivide into discrete activities, categorizing those activities that contribute best to its competitive advantage. In this way, value chain thinking is defined and a better organizational structure can be created around those activities. This value chain thinking allow organizations to identify their competitive strengths and weaknesses and therefore to reengineer their enterprise performance.

\subsection{Object Modeling of Business Processes}

Unified Modeling Language (UML) is another modeling technique that transfers an object view of an organization to a process view. UML provides a comprehensive system for designing object-oriented applications in a logical, structured manner, and is available for the development of three-tier client/server distributed applications. A basic core set of diagrams (use case models, interaction diagrams, class diagrams, and activity diagrams) are used in development process to refine the design and ultimately define the business objects, after which is coded and mapped into the organizational information system.

\subsection{Integration Strategy}

These tools and theories can now be combined, as shown in Figure 1, to model a construction business information system. The first step is to transform a functional organizational structure into a processbased structure based on the general systems modeling, value chain management, and business process reengineering.

The second step is to use the unified modeling language to build an object-oriented version of business operations that follows the organizational business rules, policies, and business process scenario. The third step is to translate the objectoriented blueprint of enterprise processes model to

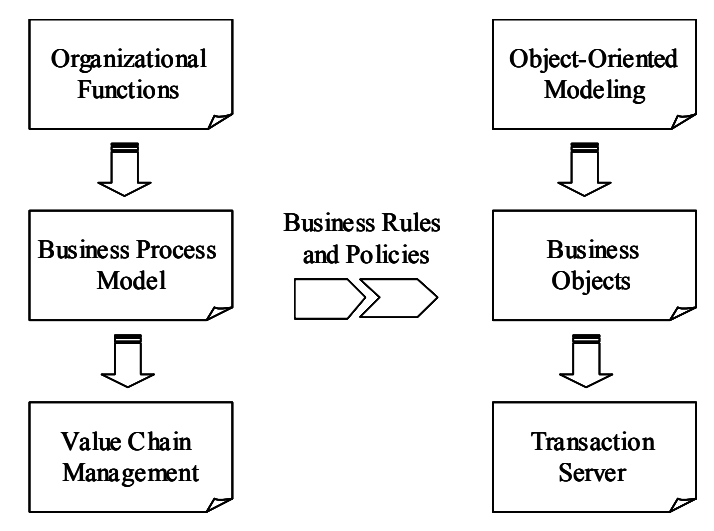

Figure 1. Overview of Object Modeling Methodology translate into machine recognizable codes and then compile them into a series reusable business objects. Several programming languages (such as $\mathrm{C}++$ and Visual Basic) can be used in this transformation. The fourth step is to migrate these business objects into a transaction system that has Internet/Intranet capability (for example, Microsoft Transaction server or the SAP R/3 Transaction Server). The business objects can reside on the project team's information system and "talk" to each other using the Common Object Request Broker Architecture (CORBA) scheme to perform over the Internet certain business functions which go beyond organizational boundaries. Regardless of location, users can participate in team coordination/collaboration and share their "collective intelligence" within a virtual corporation. This global information networking and inter-enterprise process offers enormous benefits to the construction industry, because this alignment of human and technological innovation is compatible with the nature of many construction practices.

\section{THE BUSINESS BLUEPRINT}

Consider the following progress payment example of construction subprocesses. A progress payment is a requested pay estimate to the resident engineer for quantities of completed work (see Figure 2). The resident engineer reviews the pay request to ascertain that the indicated work items comply with the actual work done; he then forwards it to the project engineer, who submits it to the owner's representative with a recommendation. If the request is approved by the owner, an account will be established and funds will be distributed to the contractor. If the request is rejected, the procedure will revert roll back to the settlement between contractor and resident engineer on the value of the work in place. To determine whether or not payment is justified, the owner's representative reviews the scope of the work and identifies its control objective. Requests for progress payment are normally submitted once a month, but weekly submitted are not uncommon if the project is larger.

\subsection{Value Chain Thinking}

According to the value chain concept, everything that a company does can be categorized into primary and support activities. In the progress payment scenario, the activities include (a) operational and execution functions of procurement and communication, (b) supplier integration to accounting and quantity systems, and (c) automated workflow and document management, all of which are incorporated into the value chain scenario for procurement logistics. The value chain depicts the subsequent workflow of converting the proposed 
supply plan for purchased work/material into commercial arrangements with the contractor/supplier, monitoring the status of these purchases, and receiving the work items for the project.

\subsection{Assembling the Model}

The progress payment is a typical business process that follows business rules and policies in the construction industry. The purpose of the Object Modeling Technique (OMT) is to select certain business functions as business objects to be coded into business applications. The use case [6] method can help to identify business objects by using descriptive statements of the procedures and functions of particular business scenarios. (e. g., the progress payment).

In this context, the pay estimate, pay request, project engineer, owner, work items, contractor, and so forth may all be viewed as business objects and a three-tier approach can be used to map the business applications and relationships with the company information system (Figure 3 ). The business objects located in the middle of Figure 3 actually reside in the application server of the IT system; on the left

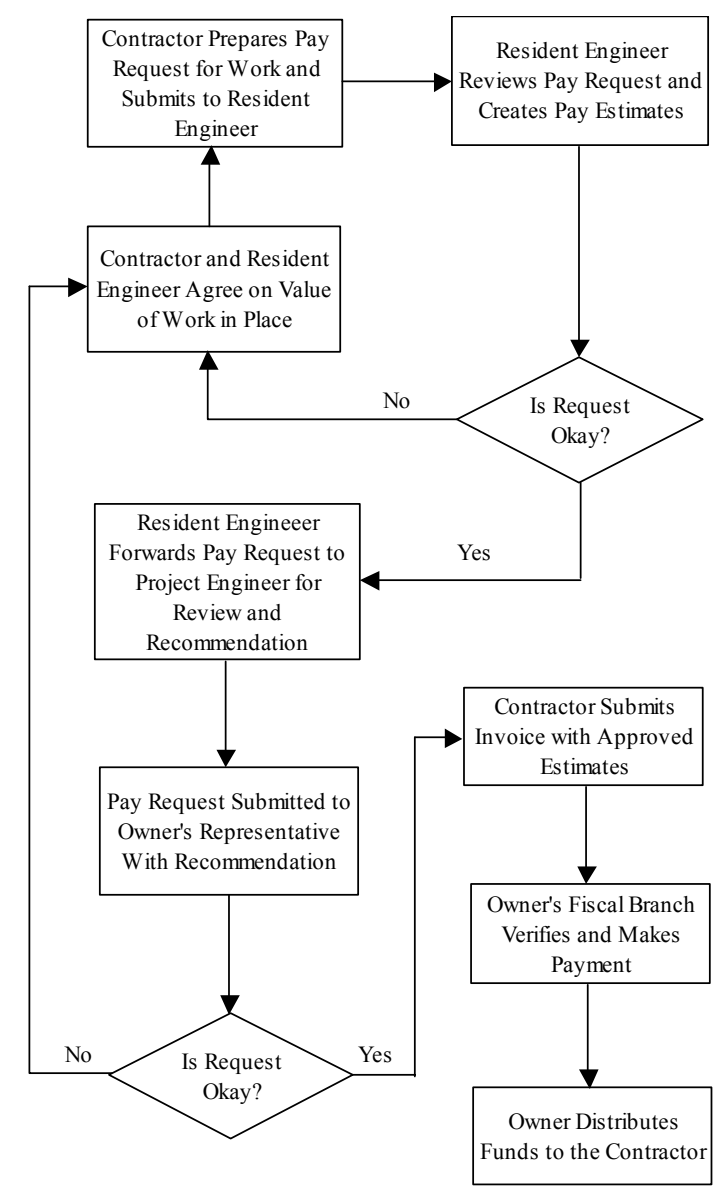

Figure 2. Progress Payment Process side is a user services layer representing the client interface that a user may need to access the system; and the data service layer on the right side represents the data storage module that corresponds to each business object.

\subsection{How It Works}

The business objects presented thus far depict business services, in that each represents something that is encountered or produced in the daily business routine. Each module in the user services part of the model actually relates to a single use case statement, which, in code terms, would actually have to be divided into a number of distinct routines. These routines deal with the methods and properties of the business objects in the business services tier, and the user interface uses instances of these objects to display needed information and feed user input into the system. The business objects, in turn, use instances of objects in the data services layer to get their data. In this way the user interface could change without impacting on the underlying way in which the application dealt with the business, and the database could be replaced with new database without affecting the rest of the system. As long as the interface to the data service objects remains intact, the rest of the code will compile and run properly. Figure 4 is a schematic diagram of a three-tier information system that store business objects to perform certain tasks for the organization.

\section{CONCLUSION}

The construction industry is both labor-intensive industry and information-intensive, and communication among participants is very important. Because a typical construction project usually involves the coordination of multi-disciplinary work efforts by different organizations and companies need to extend their technologies to their partners. In the late $1990 \mathrm{~s}$, business engineering shifted its focus from process improvement within an organization to process integration across different organizations and this is facilitated today by the growth of the Internet. Described here is an Object-Oriented approach to mapping the corporate business processes in the construction industry with IT in terms of a series of reusable business objects that can operate in the current networked environment. The advantages of this approach are (a) the tedious redesign efforts of information systems can be avoided and (b) the applications can run on different platforms. With an object-oriented approach, a business process can easily be defined and reused, and every change can be worked through a single interface to the business objects, which encapsulate the complex business rules. 
This approach enables the construction business processes to permeate different organizations, and these organizations will need to extend their technologies to outside stakeholders. Communication in this system becomes process-toprocess oriented, as opposed to the isolated IT system, and process integration across the supply chain poses a new challenge for the construction industry. The next generation of construction firms will learn that content communication is as important to software applications as technological foundations. At present, construction firms are concerned about web-enablement, which simply means the ability of software to exchange information and data over the Internet.

The dominant factor for business applications, however, is the ability to map content, such as that contained in the business blueprint, into business transactions inside and outside the organization. With a new focus on process orientation, companies will have to redesign their infrastructure. Some important areas where content and technology will coalesce to make a difference are: electronic commerce, business intelligence, data warehousing, information access, knowledge management, and data mining for relationship management. These areas will emerge in very important ways with such context-aware technologies as workflow, procedure wizard, and process agents, all of which are able to act as guides in the process environment [7].

A roadmap to the object modeling of company business processes has been outlined. This blueprint is readily available to other company applications, which will render their use much easier and help to build an adaptive business information system that extends the supply chain on the Internet. If quality was the major business issue in the 1980s, and if productivity was the major focus of business practices in the $1990 \mathrm{~s}$, adaptivity will almost certainly be the key to business practices in this decade. The object-oriented approach for IT mapping and the suggested business philosophies in this paper will enable organizations to become more adaptive. This is the essential idea of the Adaptive Business Information System (ABIS), which can be modified to support construction companies as they face the ever-changing future business environment.

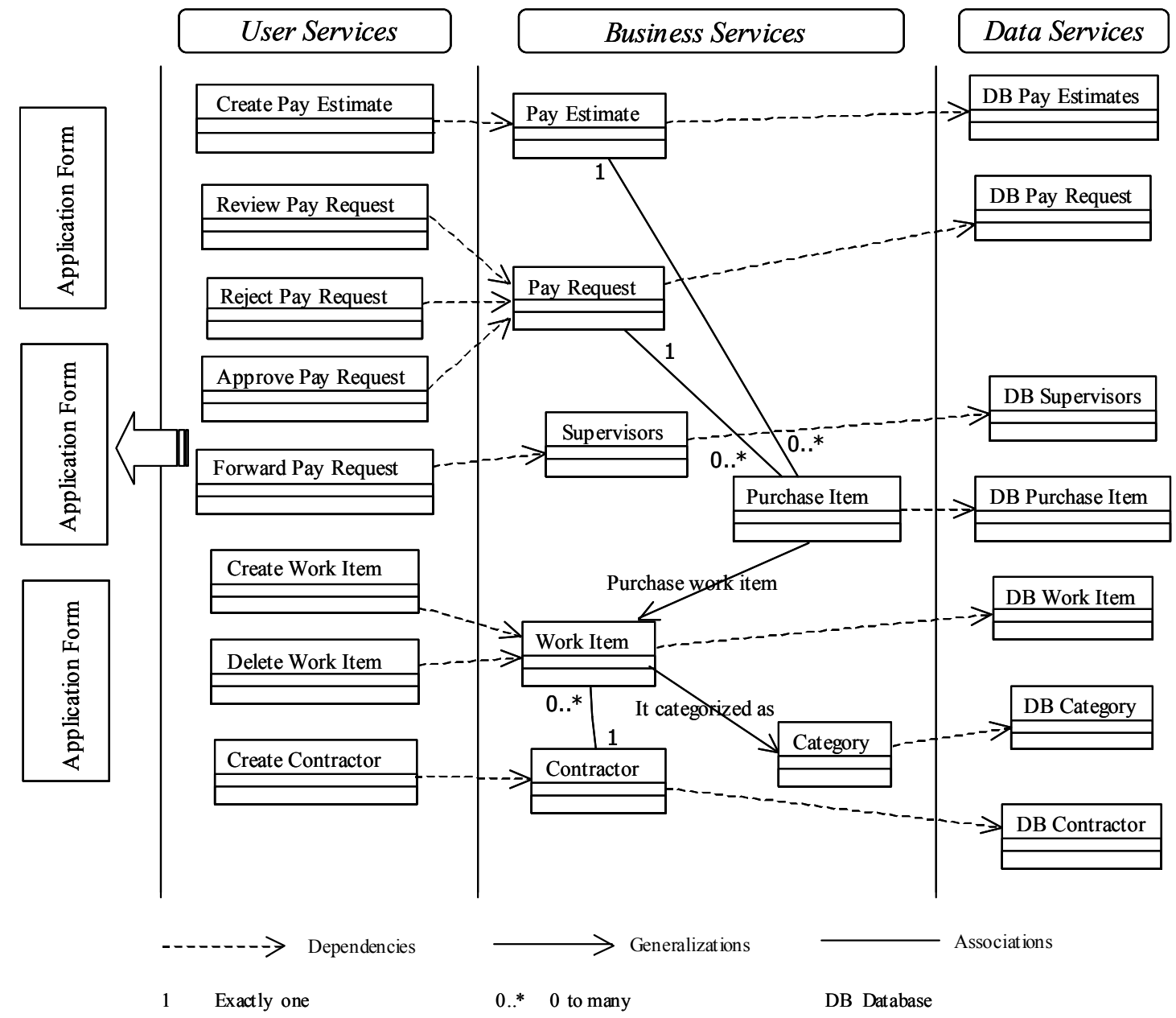

Figure 3. Object-Oriented Approach of Progress Payment in Three-Tier Service Approach 


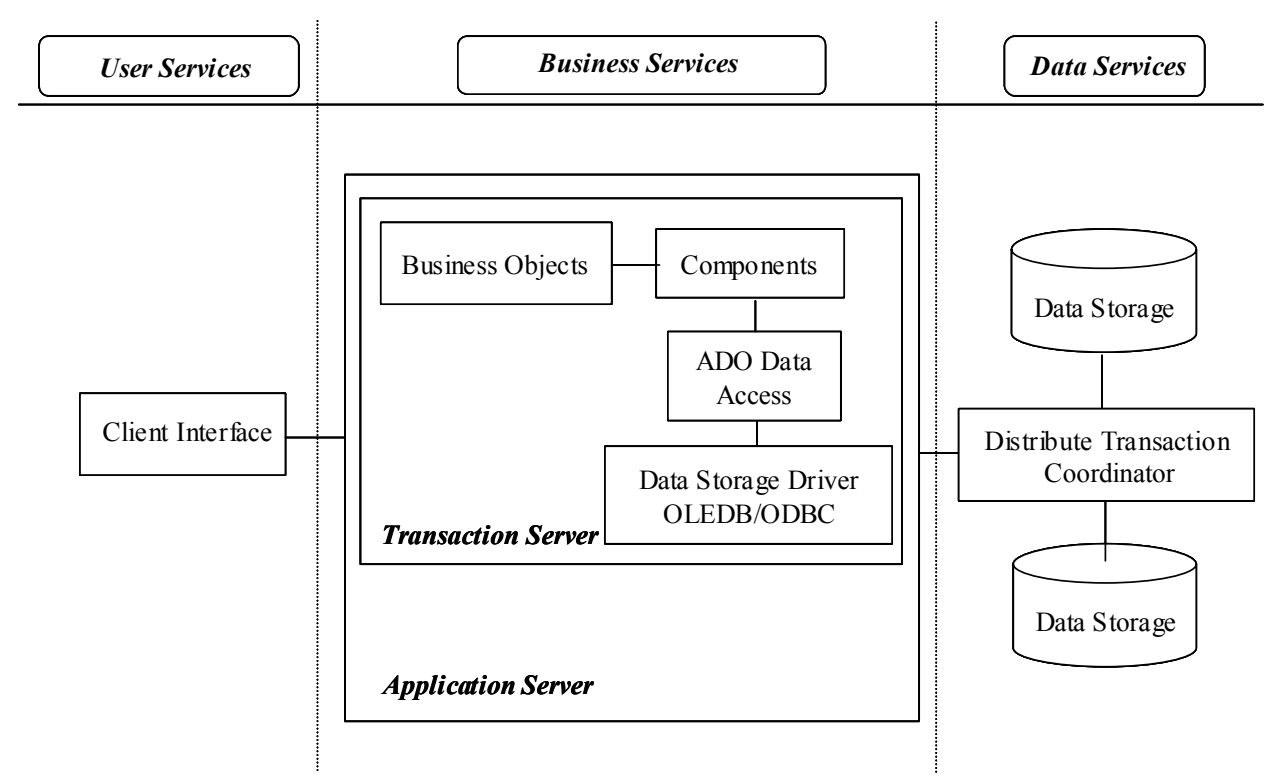

Figure 4. Schematic IT Structure for Business Object in a Three-Tier Approach

\section{REFERENCES}

[1] O. Y. Abudayyeh and W. J. Rasdorf. "Integrated Cost and Schedule Control Automation." Proceeding of ASCE $2^{\text {nd }}$ Construction Congress on Preparing for Construction in the $21^{\text {st }}$ Century, pp. 679-686. 1991.

[2] N-J. Yau, J. W. Melin, J. H. Garrett, Jr., and S. Kim. "Integrating the Processes of Design Scheduling, and Cost Estimating within an Object Oriented Environment." Proceeding of ASCE $2^{\text {nd }}$ Construction Congress on Preparing for Construction in the $21^{\text {st }}$ Century, pp. 342-347. 1991.

[3] M. Hannus. "Islands of Automation." http://cic.vtt.fi/hannus/islands.html, Technical Research Center of Finland, 1998.
[4] D. Hitchin. "A Unified Systems Hypothesis." Systems Practice Journal, Vol. 6, No 6, 1993.

[5] M. Porter. Competitive Advantage: Creating and Sustaining Superior Performance, The Free Press. 1985.

[6] I. Jacobson. "Using Objects to Develop Your Business \& IT Support-The Use Case Driven Approach." SIGS Object Expo Conference, 1994.

[7] T. A. Curran, A. Ladd, and G. Keller. SAP R/3 Business Blueprint, Understanding Enterprise Supply Chain Management, Prentice Hall, Inc. 2000. 